\title{
Gambaran Penggunaan Obat Anti Epilepsi (OAE) pada Penderita Epilepsi Berdasarkan Tipe Kejang di Poli Saraf Rumkital DR. Ramelan Surabaya
}

\author{
Eric Hartono Tedyanto ${ }^{1 *}$, Laurawati Chandra ${ }^{1}$, Olivia Mahardhani Adam ${ }^{2}$ \\ Rumah Sakit Angkatan Laut dr. Ramelan Surabaya ${ }^{1}$ \\ Departemen Ilmu Penyakit Syaraf Fakultas Kedokteran Universitas Hang Tuah \\ Surabaya ${ }^{2}$ \\ Jalan Gadung No 1, Surabaya, 60244 \\ *e-mail: erichartonoo@gmail.com
}

\begin{abstract}
Abstrak
Epilepsi merupakan gangguan susunan saraf pusat (SSP) yang dicirikan oleh terjadinya serangan (seizure, fit, attack, spell) yang bersifat spontan (unprovoked) dan berkala. Terapi utama epilepsi adalah dengan obat anti epilepsi. Pemilihan OAE didasarkan atas jenis bangkitan epilepsi. Tujuan: Penelitian ini bertujuan untuk mengetahui jenis obat antiepilepsi yang digunakan berdasarkan masing-masing tipe kejang. Penelitian ini menggunakan disain penelitian deskriptif dengan menggunakan data rekam medis penderita epilepsy. Sampel penelitian adalah pasien epilepsy yang berobat ke poli saraf. Variable yang diteliti adalah jenis epilepsy dan obat-obatan anti-epilepsi yang digunakan. Analisa data menggunakan analisa univariat. Hasil penelitian menunjukkan bahwa persentase bangkitan fokal adalah $41 \%$, bangkitan general adalah 36\% dan bangkitan tak terklasifikasikan adalah 23\%. Dari 61 sampel, persentase obat anti epilepsi yang digunakan adalah fenitoin $(31,1 \%)$, asam valproat $(21,3 \%)$ dan karbamazepin $(4,9 \%)$ sebagai monoterapi. Sementara $42,7 \%$ diterapi dengan politerapi yaitu kombinasi fenitoin, asam valproat, karbamazepin dan benzodiazepin. Tipe bangkitan fokal yang mendominasi dengan $41 \%$, bangkitan general adalah $36 \%$ dan bangkitan tak terklasifikasikan adalah $23 \%$. Obat anti epilepsi yang banyak digunakan yaitu golongan fenitoin, asam valproat dan karbamazepin sebagai monoterapi dan kombinasi fenitoin, asam valproat, karbamazepin dan benzodiazepin sebagai politerapi.
\end{abstract}

Kata Kunci: epilepsi, obat anti epilepsi, tipe bangkitan.

\section{Overview of the Use of Anti-Epilepsy Drugs (OAE) in Patients with Epilepsy Based on the Type of Seizure in Poli Saraf Rumkital DR. Ramelan, Surabaya}

\begin{abstract}
Epilepsy is a disorder of the central nervous system (CNS) characterized by attacks (seizures, fit, attack, spell) spontaneous (unprovoked) and periodically. The main treatment of epilepsy is with antiepileptic drugs. It was used the descriptive study design by using secondary data which taken at Medical Record Installation of Dr. Ramelan Naval Hospital Surabaya from September-November 2018. The results showed that the percentage of focal seizures is $41 \%$, seizures general is $36 \%$ and unclassified seizures is $23 \%$. From 61 samples, the percentage of anti-epileptic drugs used are phenytoin (31.1\%), valproic acid (21.3\%) and carbamazepine (4.9\%) as a monotherapy. While $42.7 \%$ were treated with polytherapy that the combination of
\end{abstract}


Gambaran Penggunaan Obat Anti Epilepsi (OAE) pada Penderita Epilepsi Berdasarkan Tipe... Eric Hartono Tedyanto, Laurawati Chandra, Olivia Mahardhani Adam

phenytoin, valproic acid, carbamazepine and benzodiazepines. Focal seizure that dominate with $41 \%$, the general seizure is $36 \%$ and unclassified seizures is $23 \%$. Anti-epileptic drugs that are widely used class of phenytoin, valproic acid and carbamazepine as monotherapy and the combination of phenytoin, valproic acid, carbamazepine and benzodiazepines as polytherapy.

Keywords: epilepsy, anti-epileptic drugs, the type of seizure

\section{PENDAHULUAN}

Epilepsi adalah gangguan atau kondisi medis kronis, biasanya berupa kejang berulang yang tidak dapat diprediksi, yang memengaruhi berbagai fungsi mental dan fisik. Ini adalah salah satu penyakit neurologis yang paling umum, menyerang lebih dari 3 juta orang di AS dan sekitar 50 juta orang di seluruh dunia. (Johnson, 2019) Seseorang dianggap menderita epilepsi ketika terjadi dua atau lebih kejang tanpa sebab yang dapat dijelaskan dengan kondisi medis seperti demam atau gangguan elektrolit. Kejang dapat disebabkan akibat genetic dari keluarga terhadap penyakit, atau dapat terjadi setelah cedera otak, tetapi penyebab epilepsi sebagian besar tidak diketahui. Kejang epilepsi dimanifestasikan oleh pelepasan listrik neuron yang abnormal, berlebihan, dan hipersinkron dari neuron di otak. (Goldenberg, 2010)

Diseluruh dunia diperkirakan ada 50 juta penderita epilepsi. Estimasi penderita epilepsi di Indonesia adalah 1,5 juta dengan prevalesi $0,5-0,6 \%$ dari penduduk Indonesia. (Muttaqin, 2012) Populasi epilepsi aktif (penderita dengan bangkitan tidak terkontrol atau yang memerlukan pengobatan) diperkirakan antara 4 hingga 10 per 1.000 orang. Namun beberapa penelitian di negara berkembang menunjukkan proporsi yang lebih tinggi, antara 7 hingga 14 per 1.000 orang. Secara global, diperkirakan 2,4 juta orang didiagnosis epilepsi setiap tahun. $\mathrm{Di}$ negara-negara maju, kasus baru tahunan yang terjadi antara 30 hingga 50 per 100.000 orang dalam populasi umum. Sedangkan di negara-negara berkembang, angka ini bisa sampai dua kali lebih tinggi. (WHO, 2017)

Terapi utama epilepsi adalah
dengan obat anti epilepsi (OAE).
Pemberian obat anti epilepsi ini bertujuan untuk mengontrol bangkitan epilepsi. Di Indonesia telah beredar berbagai jenis $\mathrm{OAE}$, baik yang bersifat first line (pilihan pertama) maupun second line (pilihan kedua), baik yang generik maupun yang paten. OAE lini pertama adalah carabamazepin, asam valproate, fenobarbital, dan fenitoin (Arifputra, 2014). Sedangkan OAE lini kedua adalah lamotigrine, levatiracetam, klobazam, dan topiramat. Pemilihan OAE didasarkan atas 
jenis bangkitan epilepsi. Pemilihan OAE yang tidak tepat akan mengakibatkan berlanjutnya bangkitan. Bangkitan yang terjadi berulang kali dapat menyebabkan kerusakan sel otak secara permanen. (Lukas et al, 2016)

Pemilihan OAE sudah mempunyai standar tertentu menurut WHO sebagai pedoman umum untuk diterapkan ke klinik. Namun, dalam praktek tidak jarang dijumpai adanya penyimpangan dari standar tadi. Hal ini dikarenakan pemilihan OAE juga harus mempertimbangkan aspek farmakologik obat, usia penderita, harga obat, dan cara minum obat. Contohnya pada pasien anak-anak dengan epilepsi, berdasarkan penelitian menunjukkan terjadinya masalah akademik akibat defisiensi kognitif spesifik seperti gangguan memori, gangguan persepsi pendengaran, gangguan dalam hal proses berbahasa. (Lukas et al, 2016)

Berdasarkan uraian di atas, peneliti tertarik untuk meneliti bagaimana gambaran penggunaan obat anti epilepsi (OAE) pada penderita epilepsi berdasarkan tipe kejang. Studi tentang penggunaan obat anti epilepsy penting dilakukan agar para dokter dapat menggunakannya sebagai panduan dalam mengobati pasien epilepsi

\section{METODE}

Dsain penelitian yang akan digunakan peneliti adalah penelitian deskriptif dengan metodologi penelitian studi prevalensi. Sampel yang peneliti ambil adalah semua penderita epilepsi yang didapat dari rekam medik dan memenuhi kriteria inklusi dan eksklusi.

Adapun kriteria inklusi yaitu penderita epilepsi terdiagnosis klinis dan EEG (Elektro Ensefalografi), terdapat rekam medis penderita epilepsi pertama yang mencantumkan jenis obat antiepilepsi dan tipe kejang pasien yang berobat ke poli saraf pada periode September-November 2018. Sedangkan untuk kriteria eksklusi adalah data rekam medis penderita yang tidak mencantumkan variabel yang ingin diteliti (obat anti epilepsi dan tipe kejang).

Sampel penelitian adalah pasien epilepsy yang berobat ke poli saraf pada periode September 2018 hingga Desember 2018. Variable yang diteliti adalah jenis epilepsy berdasarkan tipe bangkitan dan obat-obatan anti-epilepsi yang digunakan. Analisa data menggunakan analisa univariate dimana akan menghasilkan distribusi dan presentase dari variable yang diteliti, yaitu jenis epilepsy dan obat anti epilepsy yang digunakan.

Alat yang digunakan adalah
perhitungan dengan turus untuk
menghitung jumlah data yang ada dan


Gambaran Penggunaan Obat Anti Epilepsi (OAE) pada Penderita Epilepsi Berdasarkan Tipe... Eric Hartono Tedyanto, Laurawati Chandra, Olivia Mahardhani Adam

kemudian akan dimasukkan kedalam komputer untuk disusun dengan Microsoft word dan Microsoft excel. Data yang telah terkumpul akan dihitung menggunakan turun, dicatat diselembar kertas, kemudian data akan diolah dengan komputer menggunakan Microsoft word dan Microsoft excel dan kemudian akan disajikan dalam tabel

\section{HASIL PENELITIAN}

Berdasarkan hasil penelitian dari data rekam medik penderita terdiagnosa epilepsi yang memenuhi kriteria inklusi dan eksklusi, didapatkan jumlah sampel kasus sebanyak 61 orang dengan dengan pengambilan sampel menggunakan simple random sampling dengan distribusi sebagai berikut

Tabel 1. Distribusi frekuensi sampel berdasarkan jenis kelamin

\begin{tabular}{ccc}
\hline \multirow{2}{*}{ Jenis Kelamin } & \multicolumn{3}{c}{ Jumlah Penderita } \\
\cline { 2 - 3 } & Frekuensi (n) & Persentase (\%) \\
\hline Laki-laki & 37 & 60,7 \\
Perempuan & 24 & 39,3 \\
Total & 61 & 100 \\
\hline
\end{tabular}

Tabel 2. Distribusi frekuensi sampel berdasarkan usia

\begin{tabular}{|c|c|c|}
\hline \multirow[t]{2}{*}{ Klasifikasi Usia (th) } & \multicolumn{2}{|c|}{ Jumlah Penderita } \\
\hline & Frekuensi(n) & Persentase(\%) \\
\hline $0-14$ & 27 & 44,3 \\
\hline $15-34$ & 20 & 32,8 \\
\hline $35-64$ & 13 & 21,3 \\
\hline$>65$ & 1 & 1,6 \\
\hline Total & 61 & 100 \\
\hline
\end{tabular}

Tabel 3. Distribusi frekuensi sampel berdasarkan tipe kejang

\begin{tabular}{ccc}
\hline Tipe Kejang & \multicolumn{3}{c}{ Jumlah Penderita } \\
\cline { 2 - 4 } & Frekuensi(n) & Persentase(\%) \\
\hline Bangkitan General & 22 & 36,0 \\
Bangkitan tak Terklasifikasikan & 14 & 23,0 \\
\hline Total & 61 & 100 \\
\hline
\end{tabular}

Tabel 4. Distribusi frekuensi sampel berdasarkan jenis obat anti epilepsi

\begin{tabular}{ccc}
\hline Jenis Obat Anti Epilepsi & \multicolumn{2}{c}{ Jumlah Penderita } \\
\cline { 2 - 3 } & Frekuensi(n) & Persentase(\%) \\
\hline Asam Valproat & 13 & 21,3 \\
Fenitoin & 19 & 31,1 \\
Karbamazepin & 3 & 4,9 \\
Asam Valproat + Benzodiazepin & 3 & 4,9 \\
Asam Valproat + Fenitoin & 5 & 8,2 \\
Asam Valproat + Karbamazepin & 1 & 1,6 \\
Benzodiazepin + Fenitoin & 10 & 16,4 \\
Benzodiazepin + Karbamazepin & 3 & 4,9 \\
Asam Valproat + Benzodiazepin + Fenitoin & 2 & 3,3 \\
Asam Valproat + Benzodiazepin + Karbamazepin & 1 & 1,6 \\
Benzodiazepin + Fenitoin + Karbamazepin & 1 & 1,6 \\
\hline Total & 61 & 100 \\
\hline
\end{tabular}


Tabel 5. Distribusi frekuensi sampel berdasarkan jenis obat anti epilepsi dengan tipe kejang

\begin{tabular}{cccc}
\hline Jenis Obat Anti Epilepsi & \multicolumn{3}{c}{ Tipe Kejang } \\
\cline { 2 - 4 } & Fokal & General & Tak Terklasifikasikan \\
\hline Asam Valproat & 6 & 5 & 2 \\
Fenitoin & 5 & 10 & 4 \\
Karbamazepin & 1 & 0 & 2 \\
Asam Valproat + Benzodiazepin & 2 & 1 & 0 \\
Asam Valproat + Fenitoin & 3 & 0 & 2 \\
Asam Valproat + Karbamazepin & 0 & 0 & 1 \\
Benzodiazepin + Fenitoin & 6 & 2 & 2 \\
Benzodiazepin + Karbamazepin & 0 & 2 & 1 \\
Asam Valproat + Benzodiazepin + Fenitoin & 1 & 1 & 0 \\
Asam Valproat + Benzodiazepin + Karbamazepin & 0 & 1 & 0 \\
Benzodiazepin + Fenitoin + Karbamazepin & 1 & 0 & 0 \\
\hline Total & 25 & 22 & 14 \\
\hline
\end{tabular}

Tabel 6. Distribusi frekuensi sampel berdasarkan tipe kejang dengan tipe terapi obat

\begin{tabular}{ccc}
\hline Tipe Kejang & \multicolumn{2}{c}{ Obat } \\
\cline { 2 - 3 } & Monoterapi & Politerapi \\
\hline Fokal & 9 & 16 \\
General & 6 & 16 \\
Tak Terklasifikasikan & 4 & 10 \\
\hline Total & 19 & 42 \\
\hline
\end{tabular}

Hasil penelitian menunjukkan bahwa persentase bangkitan fokal adalah $41 \%$, bangkitan general adalah $36 \%$ dan bangkitan tak terklasifikasikan adalah $23 \%$. Dari 61 sampel, persentase obat anti epilepsi yang digunakan adalah fenitoin $(31,1 \%)$, asam valproat $(21,3 \%)$ dan karbamazepin $(4,9 \%)$ sebagai monoterapi. Sementara $42,7 \%$ diterapi dengan politerapi yaitu kombinasi fenitoin, asam valproat, karbamazepin dan benzodiazepin.

\section{DISKUSI}

Tatalaksana epilepsy adalah dengan pemberian obat anti epilepsy. Obat antiepilepsi dimulai sebagai monoterapi (1 jenis obat saja) sesuai dengan jenis bangkitan epilepsy. Pemberian obat dimulai dari dosis yang rendah dan dinaikkan secara bertahap hingga mencapai dosis efektif. Bila obat-obatan tidak adapat mengontrol epilepsy, maka bisa ditambahkan obat jenis kedua. Bila obat kedua sudah bisa mengontrol epilepsy, maka obat pertama diturunkan dosisnya. Obat antiepilepsy yang ketiga diberikan bila dua obat antiepilepsi tidak mampu mengontrol kejang. (PERDOSSI, 2011)

Tujuan tatalaksana adalah status bebas kejang tanpa efek samping. Obatobat lini pertama untuk epilepsi antara lain karbamazepin (untuk kejang tonik-klonik, kejang fokal, dan kejang pada ibu hamil), asam valproat (kejang fokal, tonik-klonik, dan absans), fenobarbital dan fenitoin 
Gambaran Penggunaan Obat Anti Epilepsi (OAE) pada Penderita Epilepsi Berdasarkan Tipe...

Eric Hartono Tedyanto, Laurawati Chandra, Olivia Mahardhani Adam

(kejang tonik klonik). (Perucca and Tomson, 2011; Sveberg et al, 2015)

Berdasarkan data hasil penelitian didapatkan bahwa untuk 1 jenis bangkitan yang sama pada tiap penderita epilepsi dapat diterapi dengan jenis obat yang berlainan. Jenis terapi yang diberikan bisa berupa monoterapi atau politerapi. Untuk monoterapi, obat anti epilepsi yang biasa digunakan adalah golongan asam valproat, fenitoin atau karbamazepin. Sementara untuk politerapi, obat yang biasa digunakan merupakan kombinasi dari golongan asam valproat, fenitoin dan karbamazepin ditambah dengan golongan benzodiazepin.

Hal ini sesuai dengan literatur yang menyebutkan obat-obatan seperti fenitoin, asam valproat, karbamazepin, dan ethosuksimid umumnya digunakan sebagai terapi lini pertama untuk kebanyakan tipe gangguan kejang. Hal ini dikarenakan obatobatan tersebut memiliki efektivitas yang sama dengan obat-obat baru yang dipasarkan, dan secara signifikan harganya lebih murah. Sebagian besar obat-obat baru (gabapentin, zonisamid, tiagabin) ini digunakan sebagai terapi adjuvan atau terapi alternatif epilepsy (Stafstrom and Carmant, 2015).

Sekitar sepertiga penderita epilepsi tidak memberikan respon dengan monoterapi, dan diperlukan kombinasi beberapa obat untuk mengontrol kejang. Penderita epilepsi dengan bangkitan fokal yang memiliki lesi struktural atau penderita dengan beberapa tipe kejang dan gangguan perkembangan membutuhkan kombinasi beberapa obat. Saat ini tidak ada panduan yang jelas dalam pemberian politerapi rasional meskipun dalam teori, kombinasi obat dengan mekanisme yang berbeda dapat berguna. Pada sebagian besar kasus, terapi awal dengan menggunakan kombinasi obat lini pertama yaitu karbamazepin, fenitoin, asam valproat, dan lamotrigine (St. Louis et al, 2009).

Fenitoin, karbamazepin, levetiracetam, dan asam valproat merupakan representatif dari obat anti epilepsi dan kurang lebih sama efektifnya dalam pengobatan kejang baik kejang umum maupun parsial (St. Louis, 2009). Dalam banyak kasus, penggunaan phenytoin atau karbamazepin sebagai monoterapi akan mengontrol kejang. Jika tidak, penggunaan asam valproat sebagai monoterapi, atau penggunaan kombinasi antara phenytoin dan karbamazepin menghasilkan kontrol yang lebih baik (St. Louis et al, 2009) Obat golongan benzodiazepin (clonazepam, clobazam) disamping sebagai antiansietas, sebagian golongan obat ini juga bermanfaat sebagai 
antikonvulsi, khususnya untuk epilepsy (Tonekaboni et al, 2012).

Penggunaan obat dalam penelitian ini sudah sesuai guideline yang ditentukan. Pasien diberikan obat anti epilepsy sesuai dengan tipe kejang. Pasien diberikan beberapa macam jenis obat antiepilepsi, ada yang monoterapi, ada yang politerapi tergantung dari kebutuhan dan respon dari pasien terhadap pengobatan. Limitasi dari penelitian ini adalah sampel yang sedikit (hanya 61 pasien) dan tidak adanya follow up jangka panjang tentang seberapa lama obat antiepilepsi efektif untuk digunakan sehingga penelitian lebih lanjut perlu dilakukan.

\section{KESIMPULAN}

Berdasarkan hasil penelitian, dapat disimpulkan penggunaan obat anti epilepsi berdasarkan tipe kejang di Poli Saraf Rumkital dr. Ramelan Surabaya sudah sesuai dengan guideline. Gambaran penggunaan obat anti epilepsi berdasarkan tipe kejang adalah tiap jenis bangkitan epilepsi ini diterapi dengan beberapa macam obat, dapat monoterapi ataupun politerapi sesuai dengan kebutuhan dan kondisi pasien, diantaranya yaitu fenitoin, asam valproat, karbamazepin, dan benzodiazepin sebagai monoterapi dan kombinasi fenitoin, asam valproat, karbamazepin dan benzodiazepin sebagai politerapi. Penggunaan obat anti epilepsi berdasarkan tipe kejang sudah sesuai dengan guideline dan memiliki outcome bagus pada pasien sehingga dapat dijadikan sebagai acuan dalam terapi epilepsi

\section{REFERENSI}

Arifputra A, Sumantri FO. Epilepsi, 2014. Dalam: Arifputra A. Kapita Selekta Kedokteran Edisi II. Jakarta (INA: Media Aesculapius)

Goldenberg MM, 2010. Overview of drugs used for epilepsy and seizures: Etiology, diagnosis, and treatment', $P$ and T. 35(7): 392415.

Johnson EL, 2019. Seizures and Epilepsy. Medical Clinics of North America. 103(2): 309-324.

Lukas A, Harsono, Astuti, 2016. Gangguan Kognitif pada Epilepsi. BIKDW. 1(2): 144-152

Muttaqin Z, 2012. Epilepsy Surgery in Indonesia: Achieving a Better Result with Limited Resources. Bali Med J. 1(2):57-63.

Persatuan Dokter Spesialis SarafIndonesia. Pedoman tatalaksana epilepsi. Edisi ke-4. Jakarta: PERDOSSI; 2011. hlm. 3-28

Perucca E and Tomson T, 2011. The pharmacological treatment of 
Gambaran Penggunaan Obat Anti Epilepsi (OAE) pada Penderita Epilepsi Berdasarkan Tipe... Eric Hartono Tedyanto, Laurawati Chandra, Olivia Mahardhani Adam

epilepsy in adults. Lancet Neurology. 10(5): 446-456.

St. Louis EK, 2009. Truly "Rational" Polytherapy: Maximizing Efficacy and Minimizing Drug Interactions, Drug Load, and Adverse Effects. Current Neuropharmacology. 7(2): 96-105.

St. Louis EK, Rosenfeld WE, and Bramley T, 2009. Antiepileptic Drug Monotherapy: The Initial Approach in Epilepsy Management', Current Neuropharmacology. 7(2): 77-82. Stafstrom CE and Carmant L, 2015. Seizures and epilepsy: An overview for neuroscientists. Cold Spring Harbor Perspectives in Biology. 5(6): a022426.

Sveberg L, Svalheim S, Taubø|l E, 2015. The impact of seizures on pregnancy and delivery. Seizure. 28: 35-38.

Tonekaboni SH, Shamsabadi FM, Anvari SS, Mazrooei A, Ghofrani M, 2012. A comparison of buccal midazolam and intravenous diazepam for the acute treatment of seizures in children. Iranian Journal of Pediatrics. 22(3): 303-308.

WHO (2017) Epilepsy Fact sheet, Media Center. 